\title{
The Internet Forums as Tool for Coping and Consultation of Mothers' with Their Child with ADHD
}

\author{
Tali Heiman \\ The Open University of Israel, Raanana, Israel
}

\begin{abstract}
The internet forums become an inseparable part for communication, information and support for parents with a child with special needs. With the rapid development of the technology, the almost unlimited access to the websites, more and more parents are seeking for online answers regarding concerns and dilemmas regarding their child with attention deficit hyperactivity disorder (ADHD) symptoms. The current study, using a qualitative study, examined 190 posts, regarding parents experience with a child with ADHD. Researchers coded the internet posts, and six main categories were derived: medical treatment; diagnosis aspects; recommendations for doctors; behavior challenges; schools and academic achievement; seeking for encouragement and support. The findings focused on the dilemmas and the enormous need for a support group among parents, suggesting planning specific online interventions with parents, in order to provide them useful social and behavioral tools, and to strength and improve their self perception and perceived well-being.

Keywords: mothers, coping, internet forums, ADHD
\end{abstract}

\section{Introduction}

Over the last decade, online support groups have become more popular and more frequently used by various groups. The internet has become an important tool for a wide variety of inter-communication, related to information seeking, consultation on health issues, sharing thoughts and emotions, and giving social support. Online discussion and the option to remain anonymous might enhance disclosure and facilitate asking questions and revealing intimate aspects of life (Barak, Boniel-Nissim, \& Suller, 2008). For example, several studies reported that the internet has become one of the most common sources for information about diseases as well as for parental support and fatherhood (Fletcher \& St. George, 2011); Romano (2007) indicated that 16\% of first-time mothers and $13 \%$ of experienced mothers rated the internet as their most important information source-Pregnant women found the internet a quick and useful tool for doctors' advice, group support, exchange of information (e.g., Legan, Sinclair, \& Kernohan, 2010). In addition, these online groups have several benefits as they enhance personal empowerment, reduce feelings of loneliness and helplessness, enable self-disclosure and the opportunity for participants to open up and express their fears and opinions (Barak et al., 2008). As only few studies have examined online discussion among mothers with a child diagnosed with ADD/ADHD, the present study seeks to explore the main issues that preoccupy such mothers to examine their main concerns, and their expressions of social support through the Internet.

Tali Heiman, Ph.D., Professor, Department of Education and Psychology, the Open University of Israel. 


\section{ADHD and Parental Coping}

ADHD is one of the most researched disorders in childhood psychiatry. The incidence of ADHD in the United States was estimated by in 2006 by the National Institute of Mental Health to be between $2 \%-8 \%$ of school-aged children, while others (Scahill \& Schwab-Stone, 2000; Zentall, Harper, \& Stormont, 1993) reported higher rates, reaching up to $18 \%$ of the entire school-age population. A considerable number of qualitative studies have focused on various aspects of the life experiences of individuals with special needs, and specifically with those of ADHD adults or of parents of ADHD children (e.g., Harborne \& Wolpert, 2004; Singh, 2004; Zentall, Moon, Hall, \& Grskovic, 2001). These studies have confirmed that both ADHD individuals and the parents of ADHD children are well aware of the struggles caused by their inability to cope with the events of daily life, including those within their families, at school or at work, or in their social environment. A qualitative study conducted on mothers with children with ADHD (Neophytou \& Webber, 2005; Singh, 2004), showed the impact of these children on parenting behaviors included emotional aspects such as intensified stress, significant changes in parents' social life, concerns regarding side-effects of medication. The difficulties encountered by parents coping with a child with a specific disorder and the inter-familial complex relationships (Heiman, 2002; Moon, Zentall, Grskovic, Hall, \& Stormont, 2001; Seipp \& Johnston, 2005) have been cited as a source of anxiety, overprotection and rigidity (Lardieri, Blacher, \& Swanson, 2000). Other studies indicated that the mothers are especially affected by their child with ADHD behaviors, and usually become more stressed (Mazzucchelli, Roberts, Studman, Sanders, \& Jeff, 2003) and distressed (Kendall, Leo, Perrin, \& Hatton, 2005). Rabiner (2006) reported that mothers with a child with ADHD were more likely to feel angry and stressed, and more likely to be engaged with their child in an active argument or disagreement, compared to the control group of mothers.

Based on the literature indicating that internet forums serve an integral tool for consultation, searching for information and seeking for support (Robledo-Ramón \& García-Sánchez, 2012), parents of children with ADHD are more involved in their child's behavior and education compared to families with children with learning disabilities. On the other hand, these parents reported higher levels of conflicts in communicating in school, and higher level of parental rejection towards the child with ADHD. Thus, the present study aimed to examine the main issues posted by the mothers with a child with ADHD, on ADHD internet forums. Furthermore, the study examined the main concerns of the mothers, i.e., what questions and dilemmas they raised, and explored participants' expectations from the ADHD forum.

\section{Method}

\section{Procedure}

A Hebrew website on ADHD was the object of this study. The Israeli larger and popular website TAPUZ (Orange) is divided into 20 different main forums according to the website's topics such as: people and society, entertainment, food and beverages, law and order, nature and animals, family, fashion, beauty and cosmetics, and each main forum has secondary forums for more topics.

The ADHD forum has a number of managers, each one expert in a different area related to attention deficit disorders. The large number of fields the forum managers are involved in make it possible for them to respond appropriately to any type of question, and almost all questions receive a quick reply. When a question is asked, forum managers and other mothers in the forum express their opinions, give advice and support the mothers who asked the question. People may address the forum managers or other participants, and specialists such as 
doctors and therapists with more specific questions. In addition, the website contains a great deal of material about attention deficit disorders and is constantly being updated. This caters to people who want to learn more about the subject.

Over a period of three months, 16 pages of questions were published. Each question raised during that period was copied, along with all the responses to it. On average, there are 15 questions per page, and each question contains a number of replies according to the number of people who responded. Some questions received no response at all while others received over 15 responses, including answers and clarifications directed to whoever asked the original question. In total, during those months there were 347 posts to the ADHD forum, of which only questions posted by mothers regarding their ADHD children were analyzed ( $n=$ 190). The five fathers who occasionally participated in the forums were excluded from the study.

Ethical aspects. After receiving approval from the Ethics Committee of the Open University for the research study, we accessed to the forums and examined the posts. Since the online communication might be delicate, personal, and even include intimate details of the participants' thoughts and feelings, we did not use any of the personal details (such as places, schools, names, etc.) during our analysis.

\section{Participants}

The study population consisted of anyone participating in the forum, asking or responding about his or her own child or responding to a question of another parent pertinent to ADHD. Each question and response or answer to the responses appearing on the forum was analyzed and the comments were summarized in tables. Since the study was conducted on a website, for the most part it was not possible to know anything about where the participants came from or about their personal, family, social or socioeconomic status. Consequently, it was not possible to classify those who addressed the forum according to any criteria. Out if the 190 people who wrote to the forum, 59 mothers of ADHD children mentioned their age, gender and education, and four but did not give any background information.

Table 1

Background Information of Participants $(n=59)$

\begin{tabular}{lcccccc}
\hline & \multicolumn{2}{c}{$\begin{array}{c}\text { Elementary School } \\
(n=25)\end{array}$} & $\begin{array}{c}\text { Middle School } \\
(n=19)\end{array}$ & \multicolumn{2}{c}{$\begin{array}{c}\text { High School } \\
(n=15)\end{array}$} \\
\hline Category & $M$ & $S . D$. & $M$ & $S . D$. & $M$ & S.D. \\
Mothers' years of education & 13.6 & 1.21 & 14.15 & 1.55 & 12.1 & 2.34 \\
Mothers' age & 37.6 & 2.88 & 39.4 & 2.7 & 42.2 & 2.9 \\
Child's age & 9.4 & 1.8 & 13.4 & 1.7 & 16.2 & 1.1 \\
\hline
\end{tabular}

As mentioned, in most cases, the participants' background was unknown. Some of the participants $(n=59$ mothers) indicated their age ranged from 32 to 46 years $(M=38.55, S . D .=2.8)$, and their educational backgrounds from ten to twenty years $(M=13.2$, S.D. $=1.7)$. The employment profiles of the mothers who mentioned it on the forums were varied and included teacher, psychologist, laboratory assistant, engineer, secretary, accountant and office manager. Results from Table 1 show no significant differences between the mothers' education, the mothers' age and the child's age (see Table 1).

\section{Data Analysis}

Qualitative data analysis procedures, as suggested by Lincoln and Guba (1985), were used to analyze the mothers' internet conversations. In order to identify and classify each of the items, the study applied a 
comparative method of analysis which included coding and categorization of the data. The procedure contained several steps: a semantic analysis was conducted: Participants' posts were read, and the main ideas, thoughts, attitudes, and requests, were coded, thus enabling identification of several categories. Once the categorizations were completed, they were compared and reviewed to identify consistencies and reconcile discrepancies. In order to maintain reliability across different raters, there was $82 \%$ exact overall agreement at the cell level. Levels of agreement were tested for chance using Kappa, which for all cells exceeded levels of agreement expected by chance at the $p<0.05$ level or better. The inter-rater coding raters scores was calculated using the correlation between raters and categories; findings ranged from 0.78 to 0.89 .

\section{Results}

The main posts and questions from the forum asked by the mothers were divided into six categories: medication; diagnostic testing; recommendations for doctors; behavior; schools and academic achievement; seeking encouragement and support. Within the ADHD forum examined, mothers could post questions to the general forum which includes anyone who joins the forum - other mothers, educators, therapeutic staff, etc. In addition, mothers could post questions to a specific specialist invited to the forum, who was predisposed to respond to mothers' problems. The differences between the general forum, and the specialists' forum will be described.

Figure 1 described mothers' posts to the general ADHD Forum, as divided into 6 main issues: medication, diagnostic testing, recommendations for doctors, school achievements, behavior, and support.

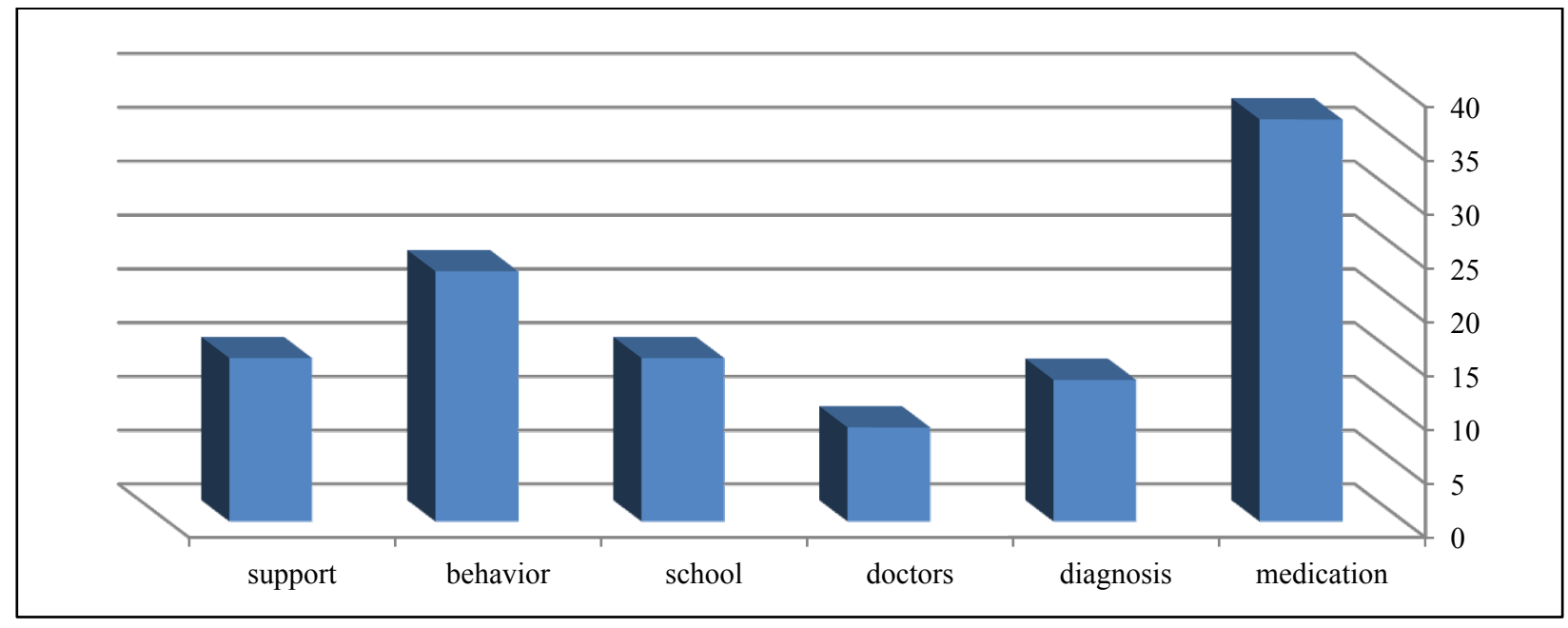

Figure 1. Mothers' posts to the general ADHD internet forum (in percentages).

Figure 1 shows that most mothers (36\%) asked for advice about medical treatment. In the second place, mothers were concerned about behavioral problems (22\%); then, mothers posted questions regarding modes of coping with the child's scholastic achievement and with the school staff (14\%); questions about diagnostic testing (12\%) and finally, mothers seeking a specialist (7\%). Mothers' questions will be described according the order of categories in Figure 1.

\section{(1) Medication}

Medication for ADHD is a topic of great concern to mothers. This category included questions asking for practical information about dosages of the medication, what time of day it should be taken, side-effects, the transition from one preparation to another, etc. 
Dosages - A question that repeated itself about the dosage of medication was: Children were taking a certain dosage, e.g., Concerta $27 \mathrm{mg}$, and mothers reported behavior problems while expecting them to decline after taking the medication, so the question was whether or not to increase the dosage. Most of the answers were that they should consult with the doctor, but even other suggested ways of thinking, together with guidance and detailed explanation about the dosage and the effectiveness of each dosage were very helpful. There was information about parallel medications, instructions for different dosages and expected changes during the transition from one medication to another.

Timing of medication-Many mothers were deliberating between different medications because of the hours of their activity. Some mothers wanted Ritalin that would help the children in their after-school club, and they were given recommendations as to when and what medication might help, after consultation with a doctor, of course. Concerta was recommended as it covered the child for 12 hours, and each child according to individual needs. In addition there were questions about experience coping with the hours during which the child needed to concentrate.

Side effects-Worried mothers related to the common side-effect of loss of appetite. Mothers asked what to do and received detailed answers from the forum managers and from other mothers when to feed the child and what kind of meal etc. For example, the mother of a six-year-old boy in first grade who takes $10 \mathrm{mg}$ of Ritalin in the morning wrote: "My question is about giving a supplement on the days he had afterschool soccer club. He loves to go to the club, but in my opinion he is not really focused on the game-more on fooling around with the other boys".

The mother received serious answers from several forum participants: check with the soccer coach how the boy is behaving; check with the boy to see what he says - whether he is having fun or finding it hard, and according to the answers see whether or not to add more Ritalin.

\section{(2) Diagnosis}

This category includes posts where people describe the state of their child and ask whether to go for diagnostic testing, whether it sounds like ADHD, what kind of testing to do and where to do it.

Is testing desirable? This question was not often asked. It seems that mothers who use the forum are interested in diagnostic testing. In many cases, not knowing causes disquiet, and so the question of whether to test or not is not an essential one. It was more of a general question - should every child who can't sit still in class be tested?

Does it sound like ADHD? This question was asked by mothers at the early stages of discovering the problem, when they feel powerless and don't know where to start in this new situation of thinking that their child might be suffering from ADHD. Many mothers analyzed their children's behavior, described the opinion of the preschool or class teacher, added their own personal opinion, and asked how it is possible that in one place the child behaves one way and somewhere else the same child behaves differently. For example, at home the child behaves nicely with siblings, but outside the child fights with friends (Kendall, Leo, Perrin, \& Hatton, 2005). The article relates to this stage in which mothers try to prove to themselves that their child is actually all right and does not have a disorder. For instance, they give the example of a child acting differently in different situations. This is the very first stage of the suspicion that there might be a problem and the attempt to escape it or deny that it exists.

Example: 
"What is the recommended way to test an 8-year-old who does not have any trouble with schoolwork: his notebooks are tidy and he does his homework by himself. The problem is behavior: he swears a lot, disrupts the lesson, runs and climbs all over the house, is very frustrated and angry. What kind of diagnostic testing is suitable? What kind of professional? Thank you."

What kind of testing? This question differed and received different answers according to the expert who answered and according to the description of the child's behavior. For instance, in a chain of questions an expert on motoric development was asked, the questions related to motoric development and the referrals to experts accordingly. In another instance, there was a question about a child that had a problem of sensory regulation, where the mother wondered whether in a setting of testing ADHD it would be possible to diagnose both disorders.

"Yossi hates it when someone combs his hair and he doesn't like to be touched at all. He would be happy not to have any physical contact at all, he hates to be kissed and hugged. He is also very 'bouncy' and climbs a lot and does things that he knows are dangerous. He is very finicky, he hates wet clothes or getting dirty from food. Is it possible that in Yossi's ADHD diagnosis they did not relate to sensory regulation? Thank you."

Recurring questions were, of course, what kind of diagnostic testing to do for ADHD, and the forum managers repeatedly gave the details of how to start the process - from the family doctor, through vision and hearing testing, and later on a psychiatrist/psychologist and neurologist for more specific areas of ADHD.

Who should we go to for testing? This is a question that also fits into the category of recommendations about doctors. There were mothers who had heard about particular psychiatrists/neurologists and, following their question about the diagnostic testing, chose to ask whether to see them. Some asked for clinics that house all the tests and others simply asked what kind of tester is suitable for a particular problem.

Example:

"About four years ago my son underwent a comprehensive psychodidactic test towards the end of 6th grade. The diagnosis recommended certain accommodations. My question is: is that diagnosis valid for when he takes his high school matriculation exams? Will he need an expansion of that diagnosis? As far as I understand it, the diagnosis is valid for 6 years. Is that true? Thank you."

The mother received detailed replies regarding the validity of the diagnosis ( 4 years), and about the borderline nature of a 6th grade diagnosis as opposed to one conducted in high school.

\section{(3) Recommendations about Doctors}

This category includes questions such as: Who knows Dr. X? Has anyone heard of neurologist Y?

It turns out that people prefer to be examined by doctors who have been recommended, especially in a field that is new to them and they are unfamiliar with. Some of the posts asked questions about specific doctors or clinics. It is worth mentioning that there were plenty of responses to these kinds of questions from forum visitors, who made recommendations based on their own experience of where to go and who to see.

Example:

"Hello everyone, I'm looking for a neurologist for a 17.5 year old boy-private and quite urgent. Any recommendations? Thanks in advance."

The replies and recommendations of forum participants were focused and many of them gave names of doctors and their area of expertise, along with a story of their own experience of satisfaction or distress. 


\section{(4) Child's Scholastic Difficulties}

The category of studies included various questions, some of which relate to the child's scholastic difficulties, while others relate to the question of which school to send the child to, or the relationship with the teacher at school.

Examples:

"Both boys have difficulties at school. The older one has issues with organization and time and the little one has difficulties with language and arithmetic."

"At school my son has trouble sitting for any length of time, he does not obey all the teachers, there are many empty pages in his work books and notebooks, homework that he mostly refuses to do."

"My child's difficulties are expressed mainly in relatively late language acquisition (reading and writing), he also finds arithmetic and English very difficult."

"The child has difficulty organizing his environment, writing in notebooks, there is a big gap between his oral verbal skills and his ability to express himself in writing."

"...he studies only what he wants to, refuses to cooperate on various things, refuses to stop solving exercises even when they move on to a different lesson. If the teacher forces him - he refuses to continue learning."

"The child cannot study for exams by himself or do homework. Also, he is very disorganized, he loses books and notebooks and so forth. He doesn't write things down in his notebooks, he loses pages handed out at school."

"Difficulties with tasks such as drawing, precision in handicraft work."

"My son's difficulties in class are remembering, copying from the board, studying for exams."

"The child is only able to study one-on-one. All the subjects are hard for him."

As is evident from the forum participants' questions and statements, the children's difficulties are typical of individuals diagnosed with ADHD, since most of them also have learning difficulties that affect the basic skills such as writing, reading and mathematics. There are also problems with organization, resistant behavior, refusal to comply with authority (the teacher) as well as difficulties concentrating and remembering. In many posts, mothers tended to give lengthy descriptions of their child's difficulties, but their questions were often not clear or focused. For example, with questions like "What should we do?" or "What do you think? Till when?" it is not always clear what kind of answer the parent is seeking. An example of a clear and focused question is that of the mother of an 11.5 year old boy, who described his difficulties at school and was looking for an alternative educational setting:

"Today he is 12 and is studying in a regular school in a special class. The educational placement committee suggested that he continue in a small class in a regular middle school. We are looking for a setting that is emotionally supportive, that will strengthen him from every point of view. Perhaps some knows of/has heard of a good place in the X region? Thank you."

A very loaded topic also included in this category is the complex relationship between mothers and school staff. On more than one occasion the forum became the center of stormy discussion following stories of mothers about treatment from a teacher, counselor or principal, e.g., a mother who was very hurt by a comment on her son's report card saying "He must concentrate more". The mother received many supportive and encouraging responses, and there were many complaints about this issue directed at the school system. It seems that mothers of ADHD children have serious grudges about their confrontations with the school. Mothers who feel their child has been mistreated by a teacher are very pained, and many mothers have similar stories, sensitivities and a sense that the teaching staff is not understanding enough and does not try hard enough to help their children advance. The posts indicate a great deal of friction between schools and mothers. 


\section{(5) Behavior Problems}

In this category, the mothers posted many statements and complaints relating to a number of their children's problems and difficulties, which are expressed in outbursts of impulsive behavior as well as social difficulties. For instance, one mother described a social game in her son's class. The boy tried very hard to surprise his classmate, but the surprise did not meet his expectations, there was a strong emotional outburst and then later on the child calmed down. Meanwhile the frustrated mother found a place to vent her feelings and get useful tips on how to cope with her son's behavior. Other mothers wrote of difficulties among siblings and about coping with various behaviors at home. There are some tips that the forum managers put up-detailed explanations about the essence and benefit of positive reinforcement, and ways to build a constructive relationship, and these were definitely appropriate for the upset mothers.

Example:

"My 9-year-old son starts the day with outbursts and swearing."

Responses to the mother came from the forum managers who suggested a step-by-step method of personal coaching how to behave with the child, give positive reinforcement and so forth. Mothers described their children's difficulties both in preschool and at school:

"Difficulty focusing on an activity without mediation, he needs help getting ready every morning, refuses to go to sleep, runs around a lot, sometimes hides from the nursery teacher, once he ran away from the nursery by crawling under the outside gate. He follows the bullies. He wins friends by giving them things."

"Outbursts of rage and violence."

"She does not last long in after-school clubs, she is easily bored."

"My son's difficulties focus mainly on behavior-He is very impulsive, restless. He has outbursts of rage and cannot accept any kind of criticism. He is very competitive and does not know how to lose graciously - it goes straight to confrontations. In class, he is capable of getting angry very easily and get into fights with classmates and, as for the teacher, he can simply get up and walk out of the classroom. He is restless, and this disturbs him and the people around him."

The mothers' comments also focus on the emotional state of their children, such as the inability to delay gratification, temper tantrums, impulsive movements, physical and verbal violence towards members of the family.

"At home he throws temper tantrums."

"There are incidents of verbal and physical violence. It is hard for him to regulate his behavior."

"At school, because of the difficulties, she lost confidence and her self-image dropped, and this led to emotional difficulties and extreme emotional reactions."

Regarding behavior, mothers also related to problems in the social arena. For example:

"It was very hard for my daughter to fit in with the class already in first grade."

"My son had social problems, lots of arguments with other children."

"The behavioral problems affect social life - difficulty understanding or reading social situations/nuances and how to react to them. The difficulties also bothered him in preschool in making and keeping friends."

"Difficulty making social contacts - no long-term 'deep' friendships with anyone in any of the settings; he doesn't know what to do when a classmate comes to visit."

"She doesn't know how to get on with her peers."

"He lacks friendship skills. He is open and likes sports and so he has no problem playing with other children, but no-one invites him home and he doesn't invite anyone either. At home he is all alone." 
Despite the division into the separate categories, the mothers' responses indicate that most children have a combination of several different problems and difficulties.

\section{(6) Encouragement and Support}

Mothers who addressed the forum, even when they had a question that was short and to the point about medication dosage or an incident at school, told the story of their child's life and described the difficulties. Even though only $15 \%$ of the posts were categorized as requests for encouragement and support, because of the integration of other questions asked in the same post, one can say that at least $50 \%$ of them included encouragement and support for forum members.

One of the purposes of the forum is to encourage and support mothers, as one of the forum managers wrote: "That's what we're here for". It is worth noting that from this point of view the forum does indeed fulfill its function-There is a great deal of empathy and emotional support for the mothers who are trying to cope. Phrases like "Keeping my fingers crossed for you", "I understand you"; compliments on handling something well "Your reaction was absolutely fine", icons of hugs and smiles really do strengthen the mothers and give them the feeling that they are not alone.

Example:

"I apologize in advance for the self-pity I am expressing here but... my son has been on Ritalin for almost a month and you can definitely see an improvement, but unfortunately, the struggle is still a daily one, for him and for us mothers, and this continual tension of 'how was he in preschool today?' gives me no rest. The sense that you cannot leave him alone for a minute. The sense that it will always be like that even with the Ritalin is very hard to bear."

The responses were sympathetic and supportive: "Don’t apologize for your difficulties". Two other forum participants wrote about their difficulties with their children despite the Ritalin. They reminded the mother that without the Ritalin things would be much worse, and so on.

\section{Transferring Information}

In addition to the mothers' questions, also found on the forum were messages relating in general to the opening of workshops around the country dealing with attention deficit, interesting articles that people had read and wanted to share, and a recommendation for seminars.

\section{Mothers Posts to the Specialist Forum}

On the ADHD website, there is awareness of the mothers' need for rapid, accessible and updated medical or paramedical information, as well as the need for experts from various fields. Therefore, every week a medical expert is invited to the forum to focus on ADHD-related areas such as a child psychologist, a pediatrician, an expert on motor skills and movement, etc. Sometimes the expert invited is not from a medical field, such as a didactic assessor, a developmental psychologist, a physical education teacher, an expert on nutrition and so forth.

Figure 2 described mothers' requests to the specialist ADHD forum. Like the general forum themes, the themes were divided into the six main issues: medication, diagnostic testing, doctors, school achievements, behavior, and support.

Figure 2 shows that the topic of medication continues to preoccupy a significant part of the mothers' posts (34\%), and similar to the general forum, behavior accounts for $21 \%$ of the posts, diagnostic testing-13\%. Unlike the general forum, there were no requests for recommendations for expert doctors; the topic of school was considerably lower on the expert forum (6\%), as was encouragement and support (2\%). 


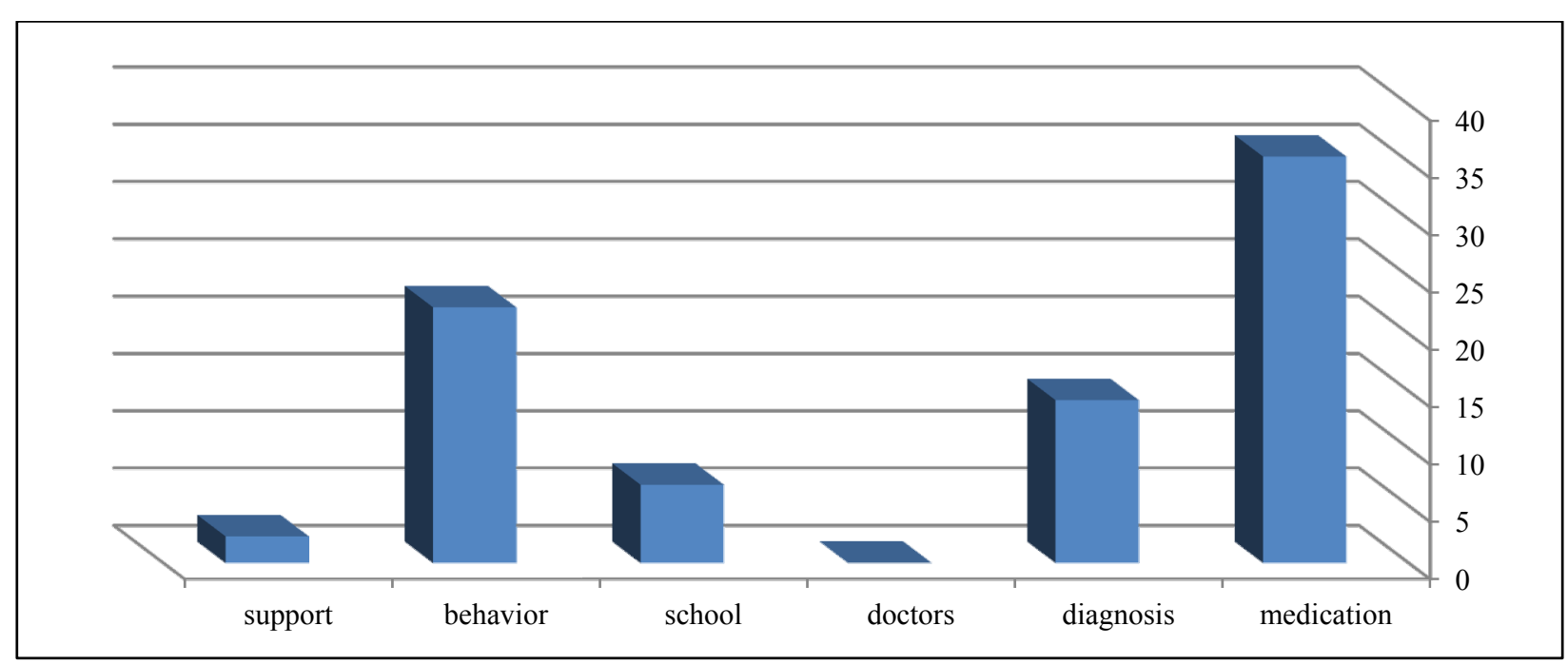

Figure 2. Mothers' request to the specialist ADHD internet forum (in percentages).

The questions addressed to the experts on the forum focused on the field of their expertise. For instance, psychiatrists and pediatricians were mainly asked questions about the various kinds of treatment using medication. Questions to the nutritionist included:

"He has trouble with certain foods and strong odors: garlic, hummous, yogurt, beetroot. When he eats, my child starts retching involuntarily. My child is very picky about food. The Ritalin suppresses his appetite in a very extreme manner."

Other questions that were bothering the participants were the child's restless behavior and how the mothers should behave at home.

\section{Frustration, Concerns, and Expectations}

Furthermore, post content frequently included direct requests for help with the current situation, but in addition, they exposed frustration and emotional reactions, general or specific concerns, and expectations from the child. Thus, in addition to the above mentioned six main categories, several sub-texts were identified as they emerged from the mothers' posts, even though they were not the main question.

Frustration. Participants expressed their frustration with the different educational or pharmacological treatments, as well with the various therapies. For example, one parent explained that after no improvement with the child's behavior, she stopped the special diet. She said, "I love my son with all my heart, but I was completely frustrated and didn't know what to do anymore". Another mother said that "after various trials with several therapists and different treatments, we noticed that our son was still suffering".

Conflict and concern. Mothers shared their dilemmas about giving their child medical treatment and expressed their concern about side effects or possible future effects of the medication such as its influence on the child's development, and about the lengthy duration of the medical treatment. These concerns were combined with certain doubts, fears and uncertainties about the treatment's efficacy. Daily coping and emotional disclosure, as described by the mothers, focused mainly on the social environment. Mothers admitted that they did not often share their thoughts, feelings or reservations about their child's behavior, mood or treatment with their friends, family members or colleagues. Some of the mothers felt discomfort when someone asked them questions about the child's behavior, "As not all of them (the friends) are supportive". 


\section{Expectations}

Most of the participants expressed the hope that their child would be able to successfully adjust to the social environment, establish mutual friendships and satisfactory social relationships, "I hope that he will gain self-control and will have more friends". Others expressed their hope that their child would finish high school successfully, find a job and become economically independent.

\section{Discussion}

The purpose of this study was to examine mothers' concerns and dilemmas associated with ADHD. The study provides further evidence of the intensity of the difficulties experienced by mothers of a child with ADHD. As noted in previous studies (Harbrone \& Wolpert, 2004; Taylor, O'Donoghue, \& Houghton, 2006), and subsequently from the mothers' posts, most of the mothers struggle daily to cope with their child's behavior. The findings provided rich data that openly described mothers' main concerns. Although some mothers described the positive changes and improvements in their children's scholastic progress, social environment and in their family relationships, most of the participants emphasized their worries, the ongoing daily struggle, and the need to bother and constantly turn to teachers, counselors and clinicians for additional explanations, help or child advocacy.

The findings revealed that medical treatment is the main worrisome topic of the discussion. Although medication is apparently applied under rigorous personal conditions, still mothers do not feel it is safe. Their desire to hear other people's recommendations, experience and effective strategies was evident in most of the posts in the forums. It appears that throughout the different posts, mothers felt willing to expose and describe their difficulties and share their distress, conflicts and intimate thoughts. As mentioned within Barak's review (Barak et al., 2008), the impression was that intimacy developed rapidly between forum members, possibly because of the anonymity of the participants, their intense need for empowerment or positive support, or as a consequence of the "online disinhibition effect" (Suler, 2005), where people feel more welcome to express themselves online, compared to face-to-face disclosure.

Furthermore, most of the mothers expressed their uneasiness with their child's scholastic achievements and social problems. Mothers stated that the teachers play, or should play, an important role in enhancing their child's learning and encouraging the child's social relationships and communication in the class setting. Since many children with ADHD are impeded by their limited attention spans and/or behavior problems (Wiener \& Daniels, 2016), this might be an opportunity to enhance or encourage the use of mothers' and teachers' supportive strategies.

Overall, the child's academic achievements - completing homework and school progress remained one of the topics mothers seek advice for, as well as coping strategies to enhance the child's motivation, time management and organization. Many mothers expressed great satisfaction with their child's ability to adopt more effective learning strategies, increased attentiveness and responsibility to do homework or carry out other tasks both in class and at home. It appears that the online communication serves as a useful tool for mothers to present their child's progress and success.

The mothers reported they were upset and disturbed by their child's social relationships, which were characterized by troublemaking, pestering, and aggressive behavior. As described in various studies (e.g., Wiener \& Daniels, 2016), children with ADHD were rejected by their peers at a very early age, mothers' complained that their children were rarely invited to their peers' homes to play, and when they brought friends home, mothers had to be constantly "on guard" in order to keep their child connected to the visitors. 
The impact of children with ADHD in our findings should be worrisome to professionals and school teachers, as mothers indicated that their experiences with various interventions (academic, behavioral or social) were in most cases frustrating and/or unsuccessful. Many mothers felt they had to initiate the diagnostic and intervention processes, usually alone. The study highlights the importance of cooperation and involvement of both mothers regarding any intervention with children with ADHD.

The mothers focused on the importance of any support, including from professional advisors, family and friends. For professional support, almost half of the participants needed to attend psychological consultation for themselves as well as for the child "the psychologist is wonderful; she has accompanied our family for several years and helps us a lot". Others receive support from a school counselor or the child's teacher. Some mothers felt that they also needed emotional backup for themselves. The non-professional support was usually provided by their partner, a close friend or a relative. Some mothers felt that their main support came from their own mother or sister, who supported and continuously advised and encouraged them.

It is worth mentioning that the existence of a support and discussion group on the internet for a specific subject has many advantages, such as the ability to reach a very large number of people from various sectors. When there are many participants in a forum, there is a chance that other mothers will get to the group website, read the problem and try to help. The people who take part in these forums are familiar with the problems and can give advice from their personal experience and thus act as a support group for the people asking the questions. And as Kendall and colleagues (2005) claimed in the studies, mothers need a supportive environment in order to be able to cope on their own with their child's disorder. The support will help the mothers themselves as well as their children to cope better in life.

\section{Limitations and Future Research}

The present research can contribute to our understanding of the experiences, perceptions, and coping of mothers with a child with ADHD. However, the findings should be viewed in the light of several limitations. First, the online posts were from one forum; second, since the study lacks descriptions of, or information about, the family members, it is difficult to provide a comprehensive picture of the mothers.

Since this is a website, important data one can obtain from interviews are lost. Another limitation is the research population: Since this is a qualitative field study, there was no possibility of selecting the mothers. A further limitation pertaining to the research population is the fact that it was not possible to find out any accurate details about a child's specific disorder-whether it was ADD or ADHD. Some mothers did not mention how old the child was, and it was also not possible to know the position of the child within the family - eldest child/second/third and so on; how many ADHD children there are in the family, the socio-economic status of the mothers, existence or lack of social support. The findings might have been more precise and specific regarding the type of post, if more detailed data such as the above had been accessible. Moreover, further study, including in-depth interviews can provide additional knowledge and perspectives on the experiences of mothers of children with ADHD.

\section{Compliance with Ethical Standards}

All procedures performed in studies involving human participants were in accordance with the ethical standards of the institutional and/or national research committee and with the 1964 Helsinki declaration and its later amendments or comparable ethical standards. 
This study received the Ethic permission of The University Committee.

\section{References}

Barak, A., Boniel-Nissim, M., \& Suler, J. (2008). Fostering empowerment in online support groups. Computers in Human Behavior, 24, 1867-1883.

Fletcher, R., \& St. George, J. (2011). Heading into fatherhood-nervously: Support for fathering from online dads. Qualitative Health Research, 21, 1101-1114.

Harbrone, A., \& Wolpert, M. (2004). Making sense of ADHD: A battle for understanding? Parents' views of their children being diagnosed with ADHD. Clinical Child Psychology \& Psychiatry, 9(3), 327-339.

Heiman, T. (2002). Parents of children with disabilities: Resilience, coping and future expectations. Journal of Developmental and Physical Disabilities, 14(2), 159-171.

Kendall, J., Leo, M., Perrin, N., \& Hatton, D. (2005). Modeling ADHD child and family relationships. Western Journal of Nursing Research, 27(4), 500-518.

Lardieri, L. A., Blacher, J., \& Swanson, H. L. (2000). Sibling relationships and parent stress in families of children with and without learning disabilities. Learning Disability Quarterly, 23, 105-116.

Legan, B. M., Sinclair, M., \& Kernohan, W. G. (2010). Internet use in pregnancy informs women's decision making: A web-based survey. Birth, 37(2), 106-115. doi:10.1111/j.1523-536X.2010.00390.x

Lincoln, Y. S., \& Guba, E. G. (1985). Naturalistic inquiry Beverly Hills. CA: Sage.

Mazzucchelli, T. G., Roberts, C. M., Studman, L. J., Sanders, M. R., \& Jeff, M. (2003). The maintenance of effects of a behavioral family intervention for families with a child who has a developmental disability. Australian Journal of Psychology, 55, 196-197.

Moon, S. M., Zentall, S. S., Grskovic, J. A., Hall, A., \& Stormont, M. (2001). Emotional and social characteristics of boys with ADHD and giftedness: A comparative case study. Journal for the Education of the Gifted, 24, 207-247.

National Institute of Mental Health (NIMH). (2006). Retrieved from http://www.nimh.nih.gov/publicat/adhd.cfm

Neophytou, K., \& Webber, R. (2005). Attention deficit hyperactivity disorder: The family and social context. Australian Social Work, 58(3), 313-325.

Rabiner, D. (2006). Getting children ready: A frustrating time for moms of children with ADHD. Attention Research Update. Retrieved from http://www.helpforadd.com/2006/november.htm

Robledo-Ramón, P., \& García-Sánchez, J. N. (2012). The family environment of students with learning disabilities and ADHD. In W. Sittiprapaporn (Ed.), Learning disabilities (pp. 129-148). InTech, DOI: 10.5772/32507.

Romano, A. M. (2007). A changing landscape: Implications of pregnant women's Internet use for childbirth educators. Journal of Perinatal Education, 16, 18-24.

Scahill, L., \& Schwab-Stone, M. (2000). Epidemiology of ADHD in school-age children. Child and Adolescent Psychiatric Clinic of North America, 9, 541-555.

Seipp, C. M., \& Johnston, C. (2005). Mother-son interactions in families of boys with attention deficit/hyperactivity disorder with and without oppositional disorder. Journal of Abnormal Child Psychology, 33(1), 87-98.

Singh, I. (2004). Doing their jobs: Mothering with Ritalin in a culture of mother-blame. Social Science \& Medicine, 59(6), 1193-1205.

Suler, J. (2005). The online disinhibition effect. International Journal of Applied Psychoanalytic Studies, 2, 184-188.

Taylor, M., O'Donoghue, T., \& Houghton, S. (2006). To medicate or not to medicate? The decision making process of Western Australian parents following their child's diagnosis with an attention deficit hyperactivity disorder. International Journal of Disability, Development and Education, 53(1), 111-128.

Wiener, J., \& Daniels, L. (2016). School experiences of adolescents with attention-deficit/hyperactivity disorder. Journal of Learning Disabilities, 49(6), 567-581.

Zentall, S., Harper, G., \& Stormont, M. (1993). Children with hyperactivity and their organizational abilities. Journal of Educational Research, 60, 143-153.

Zentall, S., Moon, S., Hall, A., \& Grskovic, J. (2001). Learning and motivational characteristics of boys with ADHD and/or giftedness. Exceptional Children, 67(4), 499-519. 